\title{
HUBUNGAN PERILAKU REMAJA PUTRI TERHADAP PEMERIKSAAN PAYUDARA SENDIRI (SADARI) \\ DI SMU NEGERI 1 KELAS III MANGGENG KABUPATEN ACEH BARAT DAYA
}

\author{
Murnita $^{1}$, Firman Parlindungan ${ }^{2}$ \\ Fakultas Kesehatan Masyarakat Universitas Teuku Umar, Meulaboh, Indonesia
}

\begin{abstract}
ABSTRAK
Pemeriksaan Payudara Sendiri (SADARI) adalah salah satu langkah deteksi dini untuk mencegah terjadinya kanker payudara. Dari 10 siswi yang diwawancarai tidak ada satupun yang mengetahui tentang SADARI. Ada 2 siswi yang mempunyai benjolan pada payudaranya. Tujuan penelitian adalah untuk mengetahui hubungan Perilaku Remaja Putri Terhadap Pemerikasaan (SADARI). Penelitian ini bersifat Analitik dengan desain cross sectional study, pengumpulan data mulai 21 oktober sampai dengan 1 november 2014 di SMU Negeri 1 Kelas III Manggeng Kabupaten Aceh Barat Daya. Populasi penelitian seluruh siswi kelas III 125 orang dengan sampel 56 siswi yang diambil dengan metode random sampling. Uji statistik menggunakan Chi-square pada tarap signifikan $95 \%$.
\end{abstract}

Hasil Penelitian menunjukkan adanya hubungan antara pengetahuan terhadap Pemeriksaan dimana $P$-Value 0,01 yang berarti lebih kecil dari 0,05 ada hubungan antara sikap terhadap Pemeriksaan dengan $P$-Value 0,27 berarti lebih besar dari 0,05 tidak ada hubungan antara tindakan remaja putri terhadap Pemeriksaan dimana $P$-Value 0,02 yang berarti lebih kecil dari 0,05 . Kesimpulannya ada hubungan pengetahuan terhadap Pemeriksaan maka hipotesis diterima, tidak ada hubungan antara sikap dengan Pemeriksaan maka hipotesis tidak diterima, ada hubungan tindakan terhadap Pemeriksaan maka hipotesis diterima. Penulis menyarakan bagi Dinas Kesehatan Aceh Barat Daya dapat memberikan penyuluhan kesekolah-sekolah agar siswi mendapat pengetahuan tentang kesehatan payudaranya, sehingga siswi dapat bertindak sesuai pemahamannya. Untuk Remaja Putri dapat meningkatkan pengetahuan dan menentukan sikap dengan melakukan pemeriksaan (SADARI) secara lebih dini. Diharapkan bagi pihak sekolah agar bekerja sama dengan petugas kesehatan untuk melaksanakan pendidikan/penyuluhan kesehatan di sekolah khususnya remaja putri untuk melakukan Pemeriksaan (SADARI).

Kata Kunci : Pengetahuan, Sikap, Tindakan dan Pemeriksaan Payudara Sendiri 
Pemeriksaan payudara sendiri (SADARI) merupakan pemeriksaan/perabaan sendiri untuk menemukan timbulnya benjolan abnormal pada payudara salah satu langkah deteksi dini untuk mencegah terjadinya kanker payudara yang akan lebih efektif jika dilakukan sedini mungkin ketika wanita mencapai usia reproduksi. Tujuan melakukan pemeriksaan (SADARI) untuk menemukan benjolan atau kanker oleh penderita sendiri. Menurut World Health Organization (WHO) dalam Septiani 2013, penyakit kanker merupakan penyebab kematian nomor 2 setelah penyakit Kardiovaskuler, setiap tahun terdapat 7 juta penderita kanker payudara dan 5 juta orang meninggal karena kanker payudara.

Di Indonesia, insidens kanker payudara tidak diketahui secara pasti. Ibrahim (2008) menyatakan bahwa, di Indonesia kanker payudara adalah jenis kanker yang menempati urutan kedua sesudah kanker leher rahim pada wanita. Menurut Profil Kesehatan Indonesia tahun 2008, kanker payudara menempati peringkat pertama penyakit kanker pada pasien rawat inap dirumah sakit pada tahun 2004-2007. Kemudian, dapat melakukan upaya pencegahan yang cepat dan tepat sehingga penyakit tersebut tidak terjadi. Jika sel kanker dapat di deteksi lebih awal, tentunya alternatif pengobatan akan semakin banyak dan presentase untuk sembuh menjadi lebih tinggi (Melissa, 2008).

Pemeriksaan payudara sendiri (SADARI) adalah sangat penting dilakukan sebagai langkah awal untuk mengetahui apakah menderita kanker payudara atau tidak adanya informasi tentang S ADARI serta kanker payudara menjadi motivasi para wanita untuk menambah pengetahuan tentang area payudara. Remaja putri dapat memeriksa payudara sendiri (SADARI) pada saat mandi dengan menggunakan jari-jari tangan sehingga dapat menentukan benjolan pada lekukan halus payudaranya. Salah satu strategi untuk meningkatkan pengetahuan dan sikap siswa terhadap kesehatan adalah melalui pendidikan kesehatan. Pendidikan kesehatan yang diberikan secara dini, akan memudahkan remaja mencapai sikap dan tingkah laku yang diinginkan yaitu sikap dan tingkah laku yang bertanggung jawab.

Berdasarkan data dari Dinas Provinsi Aceh (2013), menemukan bahwa kasus kanker payudara $25 \%$ juga ditemukan pada remaja putri 18 sampai 23 tahun serta data yang diperoleh dari poli bedah Rumah Sakit Ibu dan Anak pemerintah Aceh pada tahun 
2012, ada kunjungan pasien kanker payudara sebanyak 78 orang, dan pada tahun 2013 angka kunjungan pasien yang menderita kanker payudara meningkat sebanyak 118 orang. Sedangkan Jumlah kanker payudara yang diperoleh dari Rumah Sakit Umum Teuku Peukan Aceh Barat Daya di temukan sebanyak 38 orang wanita menderita kanker payudara dengan stadium lanjut (Rumah Sakit Aceh Barat Daya, 2013).

Berdasarkan hasil survey pendahuluan yang telah dilakukan oleh peneliti diketahui bahwa pengetahuan, sikap dan tindakan siswi terhadap pemeriksaan payudara sendiri di SMU Negeri 1 Kelas III Manggeng masih sangat kurang pengetahuan terhadap pemeriksaan payudara sendiri. Hal ini diketahui dari 10 siswi yang diwawancarai tidak ada satupun dari mereka yang mengetahui tentang S ADARI dan ada 2 siswi yang mempunyai benjolan pada payudaranya disekolah ini berdasarkan data dari Puskesmas Manggeng Aceh Barat daya. Alasan mengambil sampel penelitian di kelas III dikarenakan usia remaja di kelas III sudah mencapai usia remaja tahap akhir. Dimana usia remaja tahap akhir adalah berada pada usia 17 sampai dengan 18 tahun yaitu usia yang sudah mencapai dewasa rata-rata menduduki kelas III dan mampu meningkatkan pengetahuannya serta dapat menentukan sikap untuk melakukan praktek Pemeriksaan Payudara Sendiri (SADARI).

\section{Metodelogi Penelitian}

Jenis penelitian ini adalah jenis penelitian yang bersifat survey analitik dengan desain cross sectional, dimana variabel bebas dan variabel terikat yang terjadi pada obyek penelitian diobservasi dan di ukur dalam waktu yang bersamaan untuk mengetahui ada tidaknya hubungan dari keduanya (Notoatmodjo, 2005). Penelitian ini dilaksanakan di SMU Negeri 1 Kelas III Manggeng Kabupaten Aceh Barat Daya. Waktu penelitian dimulai dari tanggal 21 oktober sampai dengan 01 november tahun 2014.

Pengambilan populasi dalam penelitian ini adalah remaja putri SMU Negeri 1 kelas III Manggeng Kabupaten Aceh Barat Daya dengan jumlah ruangan di kelas III ada tujuh ruangan IPA ada 4 ruangan dan IPS ada 3 ruangan yaitu : Kelas III IPA $1: 18$ siswi, Kelas III IPA 2 : 18 siswi, Kelas III IPA $3: 18$ siswi, Kelas III IPA $4 \quad$ : 18 siswi, Kelas III IPS $1: 18$ siswi, Kelas III IPS 2 : 18 siswi, Kelas III IPS $3: 17$ siswi, 
sehingga total populasi ada 125 orang. Sampel adalah sebagian yang diambil dari keseluruan objek yang diteliti dan dianggap mewakili populasi. Untuk mendapatkan besarnya sampel pada penelitian ini dengan cara menggunakan rumus slovin menurut (Notoadmojo, 2005) Maka besarnya sampel minimal yang diambil pada penelitian ini adalah sebanyak 56 orang.

Tabel 1. Proporsi Jumlah Sampel SMU Negeri 1 Manggeng Kelas III Ada 7 Ruangan, IPA 1,2,3,4 dan IPS 1,2,3.

\begin{tabular}{cccc}
\hline No & Ruang Kelas III & $\sum$ Siswi & $\sum$ Sampel \\
\hline 1 & IPA 1 & $18 / 125 \times 56$ & 8 Siswi \\
2 & IPA 2 & $18 / 125 \times 56$ & 8 Siswi \\
3 & IPA 3 & $18 / 125 \times 56$ & 8 Siswi \\
4 & IPA 4 & $18 / 125 \times 56$ & 8 Siswi \\
5 & IPS 1 & $18 / 125 \times 56$ & 8 Siswi \\
6 & IPS 2 & $18 / 125 \times 56$ & 8 Siswi \\
7 & IPS 3 & $17 / 125 \times 56$ & 8 Siswi \\
\hline & Total & 125 & 56
\end{tabular}

Pengambilan sampel dilakukan dengan teknik sampling sistematis adalah teknik pengambilan sampel berdasarkan urutan dari anggota populasi yang telah diberi urut kelipatan angka genap atau angka ganjil maka untuk ini yang diambil sebagai sampel adalah nomor angka genap yaitu urutan absen dimulai dari angka 2,4,6,8 dan seterusnya (Sugiyono, 2013).

Metode pengumpulan data dalam penelitian ini adalah menggunakan kuesioner, untuk mencari informasi dari respoden tentang Perilaku Remaja Putri Terhadap Pemeriksaan Payudara Sendiri (SADARI) di SMU Negeri 1 Manggeng Kabupaten Aceh Barat Daya Tahun 2014.

Data Skunder yaitu data pendukung yang dibutuhkan peneliti yang berupa data gambaran umum lokasi penelitian, laporan tahunan tentang jumlah kanker payuadara pada stadium lanjut di Rumah Sakit Teuku Peukan Aceh Barat Daya, dari Sekolah SMU Negeri 1 Manggeng Aceh Barat Daya dan data yang mendukung dalam penelitian ini. 


\section{Hasil dan Penelitian}

SMU Negeri 1 Manggeng terletak di Desa Seunelop, tepatnya di Jalan TR Iskandar No. 2 Manggeng Kecamatan Manggeng Kabupaten Aceh Barat Daya. Nilai Akreditasi B SMU Negeri 1 Manggeng dengan type Sekolah A/A1/A2/B/B1/C/C1/C2. Jumlah Guru 52 orang, Karyawan TU 4 orang, penjaga sekolah 1 orang, penjaga pustaka 1 orang dan jumlah Siswi di Kelas III 125 orang.

Letak geografis SMU Negeri 1 Manggeng Yaitu : Utara berbatasan dengan Desa Seunelop,Timur berbatasan dengan Desa Meurandeh, Selatan berbatasan dengan Desa Tengah, Barat berbatasan dengan Desa Ujung Padang, Adapun luas lokasi SMU Negeri 1 Manggeng Kabupaten Aceh Barat Daya sebagai berikut : Luas lahan/ Tanah : 7.825,34 $\mathrm{m}^{2}$, Luas tanah terbangun : 3,648,25 $\mathrm{m}^{2}$, Luas tanah siap bangun : $1.068 \mathrm{~m}^{2}$, Luas lantai atas siap bangun : $1.058 \mathrm{~m}^{2}$, Sumber : Profil SMU Negeri 1 Manggeng 2014 .

\section{Pengetahuan Siswi}

Tabel 2 : Distribusi Frekuensi Responden Berdasarkan Pengetahuan Sis wi terhadapPerilaku Pemeriksaan Payudara Sendiri (SADARI) Di SMU Negeri 1 Kelas III Manggeng Tahun 2014

\begin{tabular}{|c|c|c|c|}
\hline No & Pengetahuan Siswi & Frek & $\%$ \\
\hline 1 & Kurang Baik & 42 & 75,0 \\
\hline 2 & Baik & 14 & 25,0 \\
\hline & Total & 56 & 100 \\
\hline
\end{tabular}

Sumber: data primer( Tahun 2014)

Sikap Sis wi

Tabel 3 : Distribusi Frekuensi Responden Berdasarkan Sikap Siswi te rhadap Perilaku Pemeriksaan Payudara Sendiri (SADARI) Di SMU Negeri 1 Kelas III Manggeng Tahun 2014

\begin{tabular}{|c|c|c|c|}
\hline No & Sikap Siswi & Frek & $\%$ \\
\hline 1 & Negatif & 18 & 32,1 \\
\hline 2 & Positif & 38 & 67,9 \\
\hline & Total & 56 & 100 \\
\hline
\end{tabular}

Sumber: data primer (Tahun 2014) 
Tindakan Sis wi

Tabel 4 : Distribusi Frekuensi Responden Berdasarkan Tindakan Sis wi te rhadap Perilaku Pemeriksaan Payudara Sendiri (SADARI) Di SMU Negeri 1 Kelas III Manggeng Tahun 2014

\begin{tabular}{clcc}
\hline No & Tindakan & Frek & \% \\
\hline $\mathbf{1}$ & Kurang Baik & 44 & 78,6 \\
$\mathbf{2}$ & Baik & 12 & 21,4 \\
\hline & Total & 56 & 100 \\
\hline
\end{tabular}

Sumber: data primer ( Tahun 2014)

Perilaku Pemeriksaan Payudara Sendiri (SADARI)

Tabel 5 : Distribusi Frekuensi Responden Berdasarkan tanggapan Sis wi te rhadap Perilaku Pemeriksaan Payudara Sendiri (SADARI) Di SMU Negeri 1 Kelas III Manggeng Tahun 2014

\begin{tabular}{clcc}
\hline No & $\begin{array}{l}\text { Perilaku Pemeriksaan } \\
\text { Payudara Sendiri (SADARI) }\end{array}$ & Frek & \% \\
\hline $\mathbf{1}$ & Tidak Tahu & 48 & 85,7 \\
$\mathbf{2}$ & Tahu & 8 & 14,3 \\
\hline & Total & 56 & 100 \\
\hline
\end{tabular}

Sumber: data primer ( Tahun 2014)

Hubungan Pengetahuan Sis wi dengan Perilaku Pemeriksaan Payudara Sendiri (SADARI)

Tabel 6 : Distribusi Hubungan Pengetahuan Sis wi terhadap Perilaku Pemeriksaan Payudara Sendiri (SADARI) Di SMU Negeri 1 Kelas III Manggeng Tahun 2014.

\begin{tabular}{|c|c|c|c|c|c|c|c|c|}
\hline \multirow[t]{3}{*}{ Pengetahuan } & \multicolumn{4}{|c|}{$\begin{array}{l}\text { Perilaku Pemeriksaan } \\
\text { Payudara Sendiri } \\
\text { (SADARI) }\end{array}$} & \multirow{2}{*}{\multicolumn{2}{|c|}{ Total }} & \multirow{3}{*}{$\begin{array}{c}\mathbf{P} \\
\text { Value }\end{array}$} & \multirow{3}{*}{$\alpha$} \\
\hline & \multicolumn{2}{|c|}{ Tidak Tahu } & \multicolumn{2}{|c|}{ Tahu } & & & & \\
\hline & $\mathrm{n}$ & $\%$ & $\mathrm{n}$ & $\%$ & $\mathrm{f}$ & $\%$ & & \\
\hline Kurang Baik & 37 & 88,1 & 5 & 11,9 & 42 & 100 & 0,01 & 0,05 \\
\hline Baik & 11 & 78,6 & 3 & 21,4 & 14 & 100 & & \\
\hline Jumlah & 48 & 85,7 & 8 & 14,3 & 56 & 100 & & \\
\hline
\end{tabular}

Sumber: data primer ( Tahun 2014) 
Hubungan Sikap Siswi dengan Perilaku Pemeriksaan Payudara Sendiri (SADARI) Tabel 7: Distribusi Hubungan Sikap Sis wi terhadap Perilaku Pemeriksaan Payudara Sendiri (SAD ARI) Di SMU Negeri 1 Kelas III Manggeng Tahun 2014.

\begin{tabular}{|c|c|c|c|c|c|c|c|c|}
\hline \multirow[t]{3}{*}{ Sikap } & \multicolumn{4}{|c|}{$\begin{array}{c}\text { Pemeriksaan Payudara } \\
\text { Sendiri (SADARI) }\end{array}$} & \multirow{2}{*}{\multicolumn{2}{|c|}{ Total }} & \multirow{3}{*}{$\begin{array}{c}\mathbf{P} \\
\text { Value }\end{array}$} & \\
\hline & \multicolumn{2}{|c|}{ Tidak Tahu } & \multicolumn{2}{|c|}{ Tahu } & & & & \\
\hline & $\mathrm{n}$ & $\%$ & $\mathrm{n}$ & $\%$ & $\mathrm{f}$ & $\%$ & & \\
\hline Negatif & 15 & 83,3 & 3 & 16,7 & 18 & 100 & 0,27 & 0,05 \\
\hline Positif & 33 & 86,8 & 5 & 13,2 & 38 & 100 & & \\
\hline Jumlah & 48 & 85,7 & 8 & 14,3 & 56 & 100 & & \\
\hline
\end{tabular}

Hubungan Tindakan Siswi dengan Perilaku Pemeriksaan Payudara Sendiri (SADARI)

Tabel 8 : Distribusi Hubungan Tindakan Siswi terhadap Perilaku Pemeriksaan Payudara Sendiri (SADARI) Di SMU Neger,6i 1 Kelas III Manggeng Tahun 2014.

\begin{tabular}{|c|c|c|c|c|c|c|c|c|}
\hline \multirow[t]{3}{*}{ Tindakan } & \multicolumn{4}{|c|}{$\begin{array}{c}\text { Pemeriksaan Payudara } \\
\text { Sendiri (SADARI) }\end{array}$} & \multirow{2}{*}{\multicolumn{2}{|c|}{ Total }} & \multirow{3}{*}{$\begin{array}{c}\mathbf{P} \\
\text { Value }\end{array}$} & \multirow[b]{3}{*}{$\alpha$} \\
\hline & \multicolumn{2}{|c|}{ Tidak Tahu } & \multicolumn{2}{|c|}{ Tahu } & & & & \\
\hline & $\mathrm{n}$ & $\%$ & $\mathrm{n}$ & $\%$ & $\mathrm{f}$ & $\%$ & & \\
\hline Kurang Baik & 39 & 88,6 & 5 & 11,4 & 44 & 100 & 0,02 & 0,05 \\
\hline Baik & 9 & 75,0 & 3 & 25,0 & 12 & 100 & & \\
\hline Jumlah & 48 & 85,7 & 8 & 14,3 & 56 & 100 & & \\
\hline
\end{tabular}

\section{Pembahasan}

Hubungan Pengetahuan Sis wi SMU Negeri 1 Kelas III Manggeng terhadap Perilaku Pemeriksaan Payudara Sendiri (SADARI)

Siswi SMU Negeri 1 Manggeng merupakan remaja yang sedang mengalami peralihan memasuki usia remaja tahap akhir yaitu ketahap remaja akhir yaitu tahap dewasa. Hal ini dapat dilihat dari tahap perkembangan fisik ketika memasuki usia remaja tahap akhir, menunjukan bahwa mereka pada tahapan peralihan dari dunia remaja ke dunia dewasa, dan penjelasan mengenai siswi dengan masa muda (Hayati 2012). Pada penelitian ini jumlah responden adalah 56 siswi. Menurut penelitian Saputri (2012) yang menunjukan bahwa tingkat pengetahuan remaja putri tentang Pemeriksaan Payudara Sendiri (SADARI) di Madrasah Aliyah Negeri (MAN) 1 Surakarta berada 
dalam kategori kurang sebanyak 87 orang $(72,5 \%)$ pengetahuan yang kurang ini menunjukkan bahwa responden kurang mengetahui atau salah dalam menjawab pertanyaan-pertanyaan yang ada di kuesioner penelitian. Menurut peneliti, siswi kurang mengetahui atau kesalahan responden dalam menjawab pertanyaan ini disebabkan oleh ketidakpahaman responden tentang Pemeriksaan Payudara Sendiri (SADARI) sehingga informasi tentang SADARI yang pernah dibaca atau didengar responden terlupakan begitu saja.

Pengetahuan remaja putri tentang SADARI sebagai deteksi dini kanker payudara di SMA Harapan 1 Yayasan Pendidikan Harapan Medan berada pada kategori baik. perbedaan hasil penelitian ini dipengaruhi oleh minat remaja putri itu sendiri untuk memperdalam guna meningkatkan pengetahuan remaja putri tentang Pemeriksaan Payudara Sendiri (SADARI) (Wahyuni, 2011). Sebagaimana yang dituliskan oleh Notoatmodjo (2005) bahwa minat sebagai suatu kecendrungan atau keinginan yang tinggi terhadap sesuatu. Minat menjadikan seseorang untuk mencoba dan menekuni suatu hal dan pada akhirnya diperoleh pengetahuan yang lebih mendalam.

Berdasarkan hasil penelitian penulis di SMU Negeri 1 Kelas III Manggeng menunjukkan bahwa dari 56 remaja putri terdapat yang berpengetahuan baik yaitu sejumlah 11 orang $(78,6 \%)$ dan tahu cara melakukan Pemeriksaan Payudara Sendiri (SADARI) tetapi tidak berminat untuk melakukannya, sedangkan 37 orang $(88,1 \%$ ) berpengetahuan kurang baik mau melakukannya tetapi tidak tahu cara melakukan Pemeriksaan Payudara Sendiri (SADARI). Dari hasil uji Chi-square didapat nilai PValue $0,01<0,05$ maka dapat disimpulkan bahwa ada hubungan antara pengetahuan remaja putri dengan Perilaku Pemeriksaan payudara Sendiri (SADARI) di SMU Negeril Kelas III Manggeng.

Pengetahuan yang tinggi belum tentu mempunyai perilaku yang baik untuk melakukan Pemeriksaan Payudara Sendiri (SADARI). Hal ini terlihat dari perilaku remaja putri yang mempunyai pengetahuan baik dan tahu cara melakukan tetapi tidak melakukan Pemeriksaan Payudara Sendiri (SADARI), dari hasil pengamatan penulis di SMU Negeri 1 Kelas III Manggeng masih juga terdapat remaja putri yang tingkat pengetahuannya baik tetapi tidak berminat untuk melakukan Pemeriksaan Payudara Sendiri (SADARI), sedangkan yang pengetahuannya kurang baik berminat melakukan 
Pemeriksaan Payudara Sendiri (S ADARI) tetapi tidak tahu cara melakukannya Padahal dengan melakukan SADARI secara dini dapat mendeteksi lebih awal tentunya alternatif pengobatan akan semakin banyak persentase untuk sembuh menjadi lebih tinggi (Melissa, 2008).

Yang dimaksud pengetahuan disini adalah merupakan segala sesuatu yang diketahui responden tentang Pemeriksaan Payudara Sendiri (SADARI). Notoatmodjo (2007) tingkat pengetahuan adalah memahami suatu objek bukan hanya sekedar tahu terhadap objek tersebut tidak sekedar dapat menyebutkan tapi dapat menginterprestasikan secara benar yakni Pemeriksaan Payudara Sendiri (SADARI) dimaksud.

Hubungan antara pengetahuan terhadap Pemeriksaan Payudara Sendiri (SADARI) dengan siswi yang berpengetahuan yang kurang baik dan yang tanggapan yang tidak tau untuk melakukan Pemeriksaan Payudara Sendiri (SADARI) dengan pengetahuan yang baik mempunyai tanggapan tau. Meskipun mereka akan mengetahui resiko yang akan dialami jika tidak dilakukan Pemeriksaan Payudara Sendiri (SADARI) sejak dini untuk mendeteksi adanya benjolan atau kanker dan akan berakibat buruk jika benjolan sudah menjadi kanker dengan mendapatkan pendidikan sedini mungkin dapat diinformasikan kepada remaja agar mereka tidak mendapatkan informasi yang salah.

Hasil penelitian ini didukung oleh hasil penelitian sebelumnya di SMA Negeri 6 Surabaya yang menyatakan bahwa ada pengaruh pendidikan kesehatan terhadap tingkat pengetahuan dan praktek Pemeriksaan Payudara Sendiri (SADARI) pada remaja putri setelah diberikan intervensi dalam hal ini pendidikan kesehatan. Ini dapat dilihat dari peningkatan nilai rata-rata setelah diberikan perlakuan pendidikan kesehatan (Alviana, 2011).

\section{Hubungan Sikap Sis wi SMU Negeri 1 Kelas III Manggeng terhadap Perilaku Pemeriksaan Payudara Sendiri (SADARI)}

Hasil penelitian penulis di SMU Negeri 1 Kelas III Manggeng bahwa sikap remaja putri terhadap Perilaku Pemeriksaan Payudara Sendiri (SADARI) diperoleh ada hubungan karena diantara remaja putri yang sikapnya positif yaitu berjumlah 33 orang, terdapat $(86,8 \%)$ yang tahu mengambil sikap terhadap Pemeriksaan Payudara Sendiri (SADARI), Sedangkan dari $15(83,3 \%)$ yang bersikap negatif terdapat yang tidak tahu 